\title{
CONTRIBUIÇÕES DA INTUIÇÃO BERGSONIANA PARA O CAMPO EDUCACIONAL: O CASO DAS CONVICÇÕES PEDAGÓGICAS
}

\author{
TATIANA CRISTINA DOS SANTOS DE ARAÚJO ${ }^{1}$
}

RESUMO: O presente artigo busca compreender a formação de professores sob a ótica do pensamento bergsoniano, no intuito de subsidiar as reflexões sobre a formação das convicções pedagógicas destes professores, enfatizando a intuição como um fenômeno relevante para esse processo. Para isso, são apresentados os conceitos de liberdade e intuição para o filósofo Henri Bergson. Posteriormente é estabelecida uma relação entre a convicção pedagógica e a intuição na visão deste filósofo. Então, são apontados os principais elementos da convicção pedagógica e as consequências desta para a prática docente. Uma das primeiras reflexões resultantes do esforço em compreender a construção das convicções dos professores consiste na ideia de estimular a reflexão em torno das experiências docentes e das vivências pessoais que repercutem sobre a prática docente. Nota-se a existência de professores que buscam de forma autônoma construir suas próprias posições, refletindo constantemente sobre as suas experiências e a sua vida intelectual. Buscam elaborar suas convicções individuais, pois estas irão nortear sua postura teórica frente à realidade prática. Tal processo reflexivo provoca, sutilmente, a autoformação destes profissionais, consistindo em um movimento interno de reflexão sobre si mesmo, seu saber e fazer pedagógico na relação com o outro.

PALAVRAS-CHAVE: Convicção Pedagógica. Intuição bergsoniana. Formação de professores.

ABSTRACT: This article aims to understand teacher training from a Bergsonian point of view, in order to support reflections on the formation of these teachers' pedagogical convictions, emphasizing intuition as a relevant phenomenon for this process. For this, the concepts of freedom and intuition are presented for the philosopher Henri Bergson. Subsequently a relationship is established between pedagogical conviction and intuition in the view of this philosopher. Then, the main elements of the pedagogical conviction and the consequences of this for the teaching practice are pointed out. One of the first reflections resulting from the effort to understand the construction of teachers' convictions is the idea of stimulating reflection on the teaching experiences and personal experiences that have repercussions on the teaching practice. Note the existence of teachers who seek autonomously to build their own positions, constantly reflecting on their experiences and their intellectual life. They seek to elaborate their individual convictions, as these will guide their theoretical position in face of their practical reality. Such reflective process subtly provokes the self-

\footnotetext{
1 Professora Associada do Departamento de Métodos e Técnicas do Ensino da Universidade Federal de Pernambuco (UFPE). Doutora em Educação pela Universidade Federal de Pernambuco (UFPE). E-mail: tatianacristinaaraujo@yahoo.com.br.
} 
formation of these professionals, consisting of an internal movement of reflection on oneself, their pedagogical knowledge and practice in relation to the other.

KEYWORDS: Pedagogical Conviction. Bergsonian Intuition. Teacher Training.

\section{Introdução}

Há muito tempo nos debatemos com o alcance de algumas metanarrativas que se julgam hegemônicas na explicação do conceito de sujeito e de suas relações com a sociedade. Um dos grandes problemas destas metanarrativas (por exemplo, a marxista, a positivista, a pragmática) é a visão absoluta que possuem sobre todas as coisas, deixando muitas vezes a sensação de "déjà vu", pois apesar de alguns dos seus princípios fundantes parecerem distintos, suas compreensões de homem e de mundo são muito próximas, pois partem de princípios universais que povoam o universo do discurso.

Nos parece que

[...] estamos de novo regressados à necessidade de perguntar pelas relações entre ciência e a virtude, pelo valor do conhecimento dito ordinário ou vulgar que nós, sujeitos individuais ou coletivos, criamos e usamos para dar sentido às nossas práticas e que a ciência teima em considerar irrelevante, ilusório e falso; e temos finalmente de perguntar pelo papel de todo o conhecimento científico acumulado no enriquecimento ou no empobrecimento prático das nossas vidas, ou seja, pelo contributo positivo ou negativo da ciência para a nossa felicidade (SANTOS, 1999, pp. 8-9).

No campo educacional, sente-se muito fortemente que essa forma de conceber o sujeito - partindo de princípios universais - está presente em quase todas as teorias que interpretam a ação pedagógica; reforçando, assim, uma condição que pouco muda em relação, por exemplo, ao próprio conceito de educação. Se observarmos a própria relação ensinoaprendizagem, podemos perceber claramente que esta se respalda, de uma forma geral, em um caráter dualista clássico, no qual a relação sujeito-objeto é marcada por um distanciamento quase obrigatório.

Contudo, acreditamos que o debate educacional deve levar em consideração as múltiplas dimensões do ser humano. Pensamos que o estabelecimento de pensamentos universais sobre o humano pode obscurecer o rico debate sobre suas singularidades, além de gestar - como pudemos observar na história - sistemas excludentes e totalitários.

Nesse contexto, pensamos a educação enquanto processo de formação humana, perspectiva evidenciada por Röhr (2013), a qual entende esse tipo de formação enquanto processo de desenvolvimento da integralidade do ser humano, ou seja, processo de 
desenvolvimento proporcional das suas dimensões básicas e transversais. Numa resumida apresentação, as cinco dimensões básicas do ser humano são: física, sensorial, emocional, mental e espiritual. As quatro primeiras situam-se no campo do imanente e a última, no campo do transcendente. Algumas das dimensões transversais do ser humano são: relacionalsocial, estético-artística, político-econômica, prático-laborial-profissional, comunicativa, místico-mágico-religiosa, volitivo-impulsional-motivacional, ética, sexual-libidinal, étnica, gênero, lúdica, ecológica (RÖHR, 2013). Outras dimensões transversais podem ser acrescentadas.

Nesse sentido, o debate em torno da integralidade humana no campo educacional não pode ficar restrito a simples questões de orientações curriculares e/ou procedimentos metodológicos, como podemos perceber nos inúmeros documentos e propostas existentes nos espaços voltados para a educação. Afinal, dessa maneira, não avançaremos num debate que problematize devidamente a tradição cartesiana de separação e hierarquização das dimensões do ser humano.

Investigar novos elementos teórico-conceituais capazes de reconfigurar a integralidade humana como resultado de nosso processo de formação humana exige novos caminhos e impulsos investigativos no âmbito educacional. Assim, acreditamos que no âmbito educacional é impossível se "[...] separar o eu pessoal do eu profissional, sobretudo numa profissão fortemente impregnada de valores e ideais muito exigentes do ponto de vista do empenhamento e da relação humana" (NÓVOA, 1995, p. 44).

Nesse contexto, pensar sobre a integralidade remete-nos à visão de suas diferentes (mas complementares) dimensões e, entre elas, a dimensão intuitiva. Dessa forma, compreendemos que entre os fenômenos que repercutem significativamente na vida do sujeito, encontra-se a intuição que, em nossa visão, é o que contribui para que muitas das experiências que ocorrem ao longo da vida fiquem registradas em nossa memória, atuando decisivamente na construção das convicções pessoais.

Sob tal enfoque, nossa perspectiva direciona-se para uma reflexão sobre a formação do professor, mais especificamente para uma aproximação de como em sua formação foram construídas suas convicções pedagógicas. Investigar as convicções pedagógicas dos professores é considerar que, no percurso de vida destes, várias vivências e experiências foram presenciadas, porém, o resultado das experiências que ficam é representado pelo tempo presente. 
É o professor que, independente da proposta de curso, está diretamente com os alunos, e se este se apresenta - em suas ações e reflexões - fragmentado ou desconectado de uma convicção, corre-se o risco de realizar um ensino que visa a uma formação apenas técnica e fragmentada ou talvez nem isso. Ter uma convicção não é condição para colaborar com a formação de alunos mais convictos de suas próprias certezas, porém, devemos refletir seriamente sobre uma ação docente que não encontra sentido em si mesma, e mais que isso, que não contribua para a autoformação do professor.

Dessa forma, esse texto busca compreender a formação de professores sob a ótica do pensamento bergsoniano, no intuito de subsidiar as reflexões sobre a formação das convicções pedagógicas destes professores, enfatizando a intuição como um fenômeno relevante para esse processo.

\section{Apontamentos para a compreensão das conviçẽoes pedagógicas de professores:} liberdade e intuição em Bergson

Mesmo não propondo uma teoria educacional, o pensamento de Henri Bergson tem possibilitado, na atualidade, uma reflexão bastante aprofundada sobre questões de natureza educativa. Esse imbricamento se justifica, talvez, pela disposição crítica que há no pensamento deste filósofo em relação às posições de matiz positivista. Como ressalta Guimarães (2006, p. 12),

perpassando a obra de Bergson, pode-se abstrair uma teoria implícita da educação. Há, entretanto, uma coerência profunda entre a gnoseologia e esta filosofia da educação, ambas apoiadas, segundo a reflexão bergsoniana, na vontade de criar, móvel fundamental do homem. Para Bergson a educação tem como objetivo conservar e aumentar o impulso vital, élan vital, fazendo desabrochar a liberdade e a criatividade.

Ainda segundo Guimarães (2006), as ideias bergsonianas exerceram uma grande ressonância na Escola Nova, na França, onde a primeira indagação de Bergson se fez ouvida: que gênero de homem pretendemos formar? E sua resposta foi clara: como não temos a previsão do futuro, fica muito difícil formar um homem, o que se pode fazer é desenvolver a liberdade das pessoas, fazer com que aflorem nelas a iniciativa e a criatividade.

Nessa direção, a filosofia de Bergson é um constante convite para que o professor seja também filósofo e esteja atento às próprias intuições. Buscar uma aproximação das experiências originárias é uma necessidade pedagógica fundamental se observarmos que, para se chegar a um pensamento sobre algo, ativamos elementos dentro de nossos espíritos, de 
nossa vida interior, o que não podemos dar conta apenas com as referências das ciências, mesmo que muitas vezes tentemos fazer isso por meio de descrições pormenorizadas.

Trata-se de algo extremamente relevante, pois, assim como Bergson, cremos na continuidade da vida interior, neste lado mais sutil da existência humana. Vida é consciência e os fatos da consciência refletem a nossa alma. Esta realidade interior é dinâmica e se movimenta em uma "continuidade indivisível e indestrutível" (BERGSON, 1994, p. 25), e ainda dura por muito tempo (o tempo da consciência). Pensar a vida como a própria duração implica pensar no tempo da consciência. Tempo que se opõe ao tempo da ciência que fragmenta a realidade para poder lhe dar simbologias. A duração, concretamente vivida, conhece-se quando tomamos consciência dela em nós mesmos. Ser verdadeiramente nós mesmos, segundo Bergson (1999, p. 217), corresponde ao "conjunto de nossos sentimentos, de nossos pensamentos e de nossas aspirações mais íntimas".

A manifestação do movimento ininterrupto dessa consciência e a aproximação da sua compreensão é o que nos leva à liberdade. Liberdade enquanto expansão do movimento permanente da própria consciência. Liberdade com que a consciência, em sua mais densa e profunda intuição, recria-se a si mesma e nesse movimento recria também a própria vida (BERGSON, 1999).

Ademais, há o "eu superficial" e o "eu profundo". Entendo que este último evidenciase "[...] onde a personalidade permanentemente está consciente, enquanto vive a melodia contínua da própria vida" (GUIMARÃES, 2006, p. 03).

Essa concepção de "eu profundo" está impregnada de liberdade, a qual lança suas raízes no eu que quer, que se apaixona, que amadurece, que é puro dinamismo e constitui a verdadeira personalidade. De fato, para Bergson, a realidade desse eu profundo é vir-a-ser, e a inteligência não capta esse dinamismo, fazendo-se necessária a presença e atuação da intuição, elemento indispensável para abarcar toda a realidade do ser. Como afirma Bergson (1978, p. 206),

É da intuição que viria a luz, se alguma vez devesse esclarecer-se o interior do
impulso vital, sua finalidade, sua significação. Porque ela estava voltada para dentro;
e se, por uma primeira intensificação nos fazia apreender a continuidade da nossa
vida interior, se a maior parte de nós não fosse mais longe, uma intensificação
superior a levaria talvez até às raízes de nosso ser e, com isso, até ao próprio
princípio da vida em geral. Acaso a alma mística não tinha precisamente esse
privilégio?

Assim, com base nas reflexões bergsonianas sobre a intuição, é possível defender como princípio a existência de um pensamento capaz de fundamentar as nossas ações pedagógicas numa realidade mais profunda do que a então reconhecida pelas teorias 
educativas da nossa época. Esta realidade encontra-se na vida interior, no espírito, e tem na duração a sua existência (DEVAUX, 2001, p. 138), na consciência profunda do nosso eu.

\title{
Imbricamentos entre convicção pedagógica e intuição
}

A reflexão filosófica acerca da intuição e da liberdade, em Bergson, permite extrair elementos importantes para a compreensão do que estamos denominando de convicção pedagógica. Trata-se de uma operação delicada e arriscada, sem dúvida, a que tentamos, pois significa reconciliar o que o filósofo preconizava em seu tempo: relacionar filosofia e vida. Não se trata de um empreendimento fácil, sabemos, já que envolve um esforço difícil e, às vezes, penoso pelo qual se rompe com as ideias preconcebidas e os hábitos intelectuais para recriar ideias que começam por serem obscuras. O mesmo vale para a validação da experiência mesma da intuição, a qual só pode ser comunicada por meio da inteligência, devendo, para lograr, transmitir-se, "cavalgar sobre as ideias".

\begin{abstract}
Desse modo, para que uma 'idéia radicalmente nova e absolutamente simples, que capta mais ou menos uma intuição' $\left(\mathrm{PM}^{2}\right.$, p. 31), torne-se clara, é necessário um trabalho de 'longo prazo'. Tal ideia, que a princípio nos aparece como 'incompreensível' e 'obscura', 'dissipará as obscuridades' presentes nos 'diversos departamentos de nosso conhecimento' e, ao dissolver os 'problemas que julgamos insolúveis', ela 'se beneficiará do que tiver feito por esses problemas' (PM, p. 32) (COELHO, 1999, p. 160).
\end{abstract}

Esse talvez seja o caso do que estamos denominando de convicção pedagógica: uma ideia nova, apreendida mais ou menos como uma intuição, e que exige um trabalho longo para torná-la reconhecível na esfera acadêmica em que circulam nossos conhecimentos. O que vamos conseguir extrair desta ideia é algo a se ver, mas, de todo modo, acreditamos ter tocado em um ponto central das lições bergsonianas e, por isso, defendemos que a construção da convicção inclui processos intuitivos.

Bergson apreende que uma ideia intuitiva se torna mais inteligível à proporção que se a aplica, e ela se mostra fecunda quando soluciona problemas "insolúveis". A questão é como expressar essas ideias tendo em vista que, segundo o próprio filósofo, a intuição não pode ser encerrada em uma representação conceitual. Ele admite que os conceitos, em certa medida, são indispensáveis, mas, ao mesmo tempo, a filosofia precisaria abandonar os conceitos prontos que estão à nossa disposição e criar conceitos diferentes. Esses adviriam da visão direta do real. Trata-se, nesse caso, como nos lembra Coelho (1999), de criar completamente, para um objeto novo, um novo conceito, talvez até mesmo um novo método de pensar.

\footnotetext{
${ }^{2}$ Coelho faz referência ao livro de Bergson "O Pensamento e o Movente" (PM).
} 
Por essa razão, Bergson caracteriza esses "conceitos intuitivos" como representações flexíveis, móveis, fluidas, ou ainda, conceitos que se remodelam sem cessar sobre os fatos.

\begin{abstract}
Depreende-se daí que o método intuitivo bergsoniano compreende dois aspectos fundamentais: o aspecto negativo, que consiste tanto na denúncia do caráter ilusório das produções da inteligência quanto na identificação da origem de certos problemas filosóficos; e o aspecto positivo, que diz respeito à solução do problema, a qual envolve a intuição propriamente dita. Deve-se considerar, ainda, que esses dois aspectos estão intimamente relacionados. Se por um lado a crítica ao entendimento cria as condições propícias para o surgimento da intuição, por outro, não se pode ignorar que as objeções à inteligência não podem ser dissociadas da resposta proporcionada pela intuição aos problemas formulados pela própria inteligência, incluindo aí a desqualificação destes (COELHO, 1999, p. 159).
\end{abstract}

Então, nota-se que, para Bergson, a intuição é tanto uma forma de conhecimento, que pode em circunstâncias específicas acontecer espontaneamente, quanto pode ser propiciada por meio de certos procedimentos analíticos, um esforço árduo e penoso por meio do qual se rompe com as ideias preconcebidas e com determinados hábitos intelectuais. Nesse sentido, a contingência seria a ultrapassagem do entendimento intelectual até o conhecimento intuitivo, proporcionando ao ser humano o contato com o ato gerador da vida e projetando a própria vida para além do determinismo (BERGSON, 2005).

Em uma síntese do pensamento bergsoniano, pode-se dizer ainda que há um impulso de vida que cria e que se desenrola num tempo real, culminando no aparecimento do ser humano constituído de consciência, memória e liberdade. Bergson entende que a realidade dura, ou seja, que existe um movimento dinâmico de ininterrupta criação. Essa duração se percebe, intuitivamente, em primeiro lugar, em nós mesmos como um eu.

\footnotetext{
Ao lado do corpo que está confinado ao momento presente no tempo e limitado ao lugar que ocupa o espaço, que se conduz como autômato e reage mecanicamente às exigências exteriores, apreendemos algo que se estende muito mais longe que o corpo no espaço e que dura através do tempo, algo que solicita ou impõe ao corpo movimentos não mais automáticos e previstos, mas imprevisíveis e livres: isto que ultrapassa o corpo por todos os lados e que cria atos ao se criar continuamente a si mesmo, é o "eu", é a "alma", é o "espírito" - o espírito sendo precisamente uma força que pode tirar de si mesma mais do que contém, devolver mais do que recebe, dar mais do que possui (BERGSON, 2005, p. 84).
}

Onde Descartes acreditava encontrar o pensamento, uma coisa que pensa, Bergson vê essencialmente uma coisa que dura. Assim, consciência para esse autor é uma espécie de conversão da atenção para o mundo interior, "afastando do campo da consciência os conceitos fabricados para satisfazer as necessidades da vida social e da conversação, e afastando as imagens depositadas em nós pela longa convivência com os objetos do mundo" (AMORIM; HABITZREUTER, 2006, p. 13). Por isso, Bergson nos convida a um desnudamento para vivenciar uma experiência de inocência com o pensamento original desprovido de conceitos. Ele nos incita a olhar em nós e aí descobrir os dados imediatos da consciência. 
Há, portanto, dois aspectos da consciência como experiência. Um no qual a consciência se ocupa das coisas externas. Outro no qual ela entra em si mesma, se toma a si mesma, aprofunda-se a si mesma. A primeira é percepção, enquanto a segunda é duração. $\mathrm{Na}$ consciência exterior, o sujeito se opõe ao objeto. Ela desdobra-se em sujeito e objeto. $\mathrm{Na}$ duração, ou consciência interior, a consciência é uma continuidade em que os momentos não se individualizam uns em relação aos outros e não se opõem ao eu que os vivencia. Essa consciência forma um todo que é a própria pessoa.

A memória, por sua vez, é a responsável por armazenar aquilo que é pensado, visto e desejado desde o primeiro aflorar de nossa consciência (Bergson, 1979). Por isso,

co-extensiva à consciência, ela (memória pura) retém e alinha uns após outros todos os nossos estados à medida que eles se produzem, dando a cada fato seu lugar e consequentemente marcando-lhe a data, movendo-se efetivamente no passado definitivo, e não, como a primeira (memória hábito), num presente que recomeça a todo instante (BERGSON, 1999, p. 177).

Mais especificamente, a memória teria como função mais preeminente

evocar todas as percepções passadas análogas a uma percepção presente, recordarnos o que precedeu e o que seguiu, sugerindo-nos assim a decisão mais útil. Mas não é tudo. Ao captar numa intuição única momentos múltiplos da duração, ela nos libera do movimento de transcorrer das coisas, isto é, do ritmo da necessidade. Quanto mais ela puder condensar esses momentos num único, tanto mais sólida será a apreensão que nos proporcionará da matéria (BERGSON, 1999, pp. 266-267).

Disso tudo, depreende-se a relação entre duração, memória e liberdade. A duração, sendo consciência e memória, faz surgir a liberdade pelo fato de que é também criação. E criação em Bergson não supõe causalidade, determinismo ou finalismo. É essencialmente um ato livre, contingente. A própria sucessão na duração já supõe a liberdade, pois a verdadeira liberdade é criação de si mesmo por si mesmo, não é uma opção de escolha entre fatos dados, mas uma escolha em criar fatos novos.

O que nos sobrevém é sempre novo, desconhecido, imprevisível. E nisso a duração é a própria originalidade, porque nela nada se repete. A liberdade consiste no algo mais que é criado. Este algo mais não é de ordem quantitativa, mas quer dizer outro, diferente, novo, algo novo qualitativamente, de caráter imprevisível (AMORIM; HABITZREUTER, 2006, p. 14).

A liberdade em Bergson (s/d) emerge como um esforço de interiorização. Esforço que à medida que vai se aprofundando faz despontar novas dimensões da liberdade. Desse modo, a liberdade se faz como um dinamismo criador que é o próprio ser verdadeiro. Com essa experiência de liberdade, o homem ultrapassa suas limitações ordinárias e, ao mesmo tempo, trilha o caminho para a constituição de suas convicções.

Nessa perspectiva, o processo de formação de uma convicção está diretamente relacionado ao que, no pensamento bergsoniano, compreende-se como liberdade. As nossas 
convicções mais profundas se originariam ao longo do processo existencial, em um movimento de recriação de si mesmo, no encontro com a sua própria duração. As convicções se processariam na duração, projetando na vida a autenticidade do nosso próprio "eu". Desse modo, suspeitamos que as convicções pedagógicas originam-se na nossa realidade interior.

Embora admitamos que as convicções possam ser alimentadas também das experiências superficiais, é na realidade profunda que uma determinada convicção vai encontrar seu solo de enraizamento, diferindo, por exemplo, dos dogmas e das crenças adquiridas externamente. Um dos elementos importantes no florescimento dessas convicções é exatamente a experiência intuitiva. O fenômeno intuitivo é algo que nos acontece mais comumente do que imaginamos, contudo ele passa por nós sem que tenhamos a clareza do seu impacto sobre nossas construções cotidianas.

Mas mesmo que não tenhamos consciência, as experiências significativas ficam registradas em nossa memória e podem refletir-se em ações que colaboram com a nossa construção identitária. Por isso, a intuição, mesmo que comunicada de forma "incompleta", pode ser expressa através da inteligência, sendo intermediada frequentemente por imagens. Embora as imagens não sejam a intuição, elas aproximam-se dela mais que os conceitos, podendo agregar-se a eles para fornecer a intuição. Como nos diz Coelho (1999, p. 162),

\begin{abstract}
em L'intuition philosophique, o filósofo define a imagem como 'quase matéria, pois se deixa ainda ver, e quase espírito, pois não se deixa tocar' (PM, p. 130). Essas imagens, que derivam da intuição, são indispensáveis para apreendê-la. Elas são necessárias para 'obter o signo decisivo, a indicação da atitude a tomar e do ponto para onde olhar'.
\end{abstract}

\title{
Apontamentos sobre a convicção e sua relevância para o debate educacional
}

Com esses rápidos apontamentos extraídos do diálogo com a teoria bergsoniana, acreditamos ser possível destacar que uma convicção pode ser pensada como uma certeza profunda acerca de algo. Certeza que pode ser identificada, por aproximações, nas atitudes do indivíduo e, no caso dos professores, em seu agir pedagógico.

Pensamos que essa aproximação não é algo extemporâneo, pois, seguindo a compreensão de Japiassú e Marcondes (1996, p. 55), para quem a convicção configura-se como um "grau bastante forte do assentimento que se interioriza", vislumbra-se que uma convicção não se instala, como nos diz Bergson, mediante um olhar superficial sobre alguma coisa, mas a partir de uma íntima certeza construída por reflexões profundas do eu. Nessa mesma direção, Durozoi (1993), Luft (1995), Torrinha (1939) e Fernandes (1998) reforçam a ideia de uma certeza íntima que se constrói sobre algo. Certeza atrelada à persuasão íntima - 
do latin persuadio, conscientia -, uma opinião firme que se tem sobre algo, a convicção, conviction (inglês), conviction (francês) ou convictus (latim). Dessa forma, a palavra convicção aponta para certeza profunda e pode apontar uma aproximação intuitiva ao conhecimento sobre as coisas que se refletem na vida dos indivíduos.

Ainda sobre o termo convicção, Abbagnano (1982, p. 208) apresenta uma idéia próxima às demais, porém acrescenta uma compreensão kantiana sobre o termo. Para Kant, na Crítica da Razão Pura, a convicção representa uma crença e é "válida para todos, desde que estes sejam dotados de razão, o fundamento dessa crença é objetivamente suficiente". Embora concordemos com a relevância do argumento kantiano, em nossa compreensão as características apontadas por Kant para a convicção seriam insuficientes, pois, tomada como regra do agir, uma convicção não seria necessariamente válida para todos.

Dentro de nossa compreensão, a convicção porta dimensões subjetivas e objetivas, visto que não construímos convicções sem esforço próprio; isto é, para chegarmos à convicção de algo nosso pensamento procede por idas e vindas, baseado em princípios que fundamentam racionalmente nossas escolhas, mas que são assumidos, convictamente, como um ato de liberdade. Assim, a convicção não é uma certeza que se instala logo ao nascermos e que continua a mesma durante toda a vida. Se assim fosse, o comportamento humano já estaria determinado ao nascermos. As convicções são construídas a partir de movimentos do nosso pensamento, oscilando entre princípios subjetivos e objetivos até chegar à certeza profunda sobre algo.

A convicção está relacionada ao que, no pensamento bergsoniano, pode-se associar ao próprio movimento da existência. Nessa perspectiva, as convicções mais profundas se originam ao longo do processo existencial de cada indivíduo, num movimento de recriação de si mesmo, na coincidência com a sua duração. É desse processo existencial que podemos dar conta, pois dele "estamos mais certos e [...] melhor conhecemos [...], pois de todos os outros objetos temos noções que podem ser julgadas exteriores e superficiais, ao passo que percebemos a nós mesmos interiormente, profundamente" (BERGSON, 2005, p. 01). A fim de apreender esse processo,

não é necessário associar vários fatos de consciência para reconstituir a pessoa: toda ela se encontra num só deles, contanto que se saiba escolher. E a manifestação exterior deste estado interno será precisamente o que se chama um ato livre, porque só o eu será o seu autor, uma vez que ela exprimirá o eu total. Neste sentindo, a liberdade não admite o caráter absoluto que o espiritualismo lhe empresta, por vezes admite graus (BERGSON, 2006, p. 116).

Desse modo, 
enquanto se assiste a um espetáculo ou se participa de uma conversa, surge, de repente, a convicção de que já se viu o que se vê, já se ouviu o que se ouve, já se pronunciaram as frases que se pronunciaram - que esteve ai, no mesmo lugar, nas mesmas disposições, sentindo, percebendo, pensando e querendo as mesmas coisas - enfim, de que se revive nos mínimos detalhes alguns instantes da vida passada. Algumas vezes, a ilusão é tão completa que a todo momento, enquanto dura, acredita-se nela a ponto de predizer o que vai acontecer: como já não sabemos, uma vez que sentimos que teremos sabido? (BERGSON, 2006, pp. 95-96).

Essa sensação de ser estranho a si mesmo, por estar diante de situações que convictamente se crê já ter presenciado, mas não podendo compreender racionalmente, pois são situações do presente, é o que Bergson chama de "despersonalização"3, termo este relacionado - mas não sinônimo - a "falso reconhecimento". O falso reconhecimento nos leva a fazer várias observações do acontecimento, assumindo muitas vezes expressões idênticas.

O alcance de uma convicção é o resultado de um profundo processo do pensar que é criativo e não ingênuo. De fato, é a própria liberdade em manifestação, pois quando atingimos a convicção sobre algo, ela não é uma simples escolha entre duas vias; se assim o fosse seria também dogma e não convicção. Para ser livre, o "eu" não deve explicações do motivo que o levou a tomar certas decisões, já que "é da alma inteira que emana a decisão livre; e o acto será tanto livre quanto mais a série dinâmica a que se religa tender para se identificar com o eu fundamental" (BERGSON, s/d, p. 117). Muitos irão viver e morrer "sem terem conhecido a verdadeira liberdade" (idem).

Ao pensar a convicção como uma questão educativa relevante, busca-se ultrapassar uma visão fragmentada da realidade, ou melhor, solicita-se uma visão de educação mais integral. Não estamos sós nesse empreendimento. Seguindo Guimarães (2006), acreditamos que a reflexão gnoseológica de Bergson permite uma análise renovada dos pressupostos que ancoram os processos educacionais. Mais ainda, segundo Guimarães (idem, p. 06),

Bergson concebia a educação como uma formação integral, na qual os aspectos moral, intelectual, sociológico e físico têm seu lugar assegurado de direito. Bergson quer aliar, no ensino, o esprit de géometrie (estudos científicos) com o esprit de finesse (estudos culturais), tornando equilibrada e harmoniosa a educação. Se nos atentarmos para o ensino tradicional, veremos um ensino meramente informativo, acumulativo e enciclopédico, que não é formativo. Uma indisciplina que pode comprometer o élan vital, presente no educando. O élan vital que é sempre exigência motivada de criação, renovação e estímulo.

É nesta perspectiva que procuramos no pensamento de Henri Bergson elementos que permitissem a compreensão de determinados processos que atravessam a educação dos seres humanos, embora nem sempre esses processos sejam tomados em sua consistência própria,

\footnotetext{
${ }^{3}$ Bergson menciona este termo que, segundo ele, foi criado por M. Douglas (Um caso de despersonalização, Revue Philos, vol. XIV, 1898, pp. 500-507).
} 
como é o caso das experiências intuitivas. A dificuldade de encontrar uma linguagem que permita expressar o fenômeno da intuição não pode ser uma justificativa para relegar o papel educativo desse fenômeno. $\mathrm{O}$ argumento comumente veiculado de que "a intuição é inerentemente inexplicável” (PARIKH; NEUBAUER; LANK, 1998, p. 79), ancorado na conceituação da intuição do próprio Bergson que a qualifica como inexprimível, passa ao largo das análises que ele próprio realizou no sentido de evidenciar que o caráter inexprimível refere-se não à impossibilidade de expressar algo da intuição, mas de não se poder alcançar, de forma absoluta, o que cada ser tem de único. Assim, não há nada que impeça uma abordagem da intuição mediante aproximações, inclusive intelectuais, já que, como também reconhece Bergson, o intelecto é necessário e imprescindível para o conhecimento e o estudo de um dado objeto. O cuidado metodológico, quando da aproximação com a temática, aponta apenas que a análise não retratará fielmente a vivência original. Tomado esse cuidado, o estudo da intuição enquanto vetor formativo das nossas convicções pedagógicas constitui-se de uma importância fundamental para a "formação" dos professores.

Nesse sentido, os apontamentos discutidos têm como intenção afirmar que a formação de professores também é um problema filosófico, isso porque toda a educação e toda formação remete-nos a um determinado conceito de ser humano e de suas relações com o mundo. Logo, como educadores, precisamos estar atentos aos nossos processos intuitivos, pois muitas vezes buscamos a explicação para os grandes problemas humanos e educacionais em instâncias distantes de nossa própria autenticidade.

Daí a relevância de se analisar a construção das nossas convicções pedagógicas e seus impactos nas decisões e práticas cotidianas. Admitimos, portanto, que há uma interface entre o que aqui chamamos de convicção profunda e o que Henri Bergson chama de intuição íntima das coisas.

\section{Conclusões}

Endossamos a necessidade de percorrer as linhas tênues da reflexão acerca da formação de professores levando em conta os aspectos sutis que a acompanham, como a intuição e a convicção pedagógica, haja vista que estes aspectos também são relevantes para a tomada de decisão do professor ante as exigências do fazer pedagógico na atualidade. Entendemos que este esforço é necessário se queremos, de fato, contribuir para uma formação humana.

Por isso, uma das primeiras reflexões que extraímos desse esforço em compreender a construção das convicções dos professores consiste na ideia de estimular a reflexão em torno 
das experiências docentes e das vivências pessoais que repercutem sobre a prática docente. Este estímulo deve ser direcionado para os atuais professores e, sobremaneira, para os futuros. Pois, como Bergson (2005, p. 244), acreditamos que "não há obstáculos que vontades suficientes esforçadas não possam quebrar, se a isso se aplicarem a tempo".

Isso se faz necessário porque, durante o aprendizado da docência, os professores se defrontam com momentos de desequilíbrio e sentimentos de insegurança gerados por situações que não podem controlar e, justamente pelo caráter desafiador delas, são levados a refletirem sobre suas convicções pedagógicas. Aqui, vale ressaltar que nem todos os professores conseguem ou se permitem fazer tais reflexões.

Ante este cenário, sabemos que existem professores com receio de deixar suas antigas e seguras posições teóricas e práticas, optando então por resistir a mudanças exigidas pela sociedade em transformação, assumindo para si os paradigmas antigos como verdade única. Nessa postura eles defendem cegamente os princípios que sustentam o paradigma em crise e recusam muitas vezes mudar, sem ter um conhecimento mais aprofundado dos paradigmas emergentes. Contrapomos a postura destes professores ao pensamento de Bergson (1979, p. 18) sobre a existência de um ser consciente: existir significa mudar amadurecendo, "amadurecer criando-se infinitamente a si mesmo".

Há também aqueles que estão sempre procurando novas tendências e, nessa busca incansável, aderem sempre ao que é mais inovador, independente dos princípios desta tendência. Desse modo, vemos novamente uma prática docente que não encontra respaldo do "eu profundo", agindo apenas, como diria Bergson (1978), dentro de uma perspectiva superficial do eu.

Existem também aqueles professores menos vulneráveis aos dogmatismos do passado e aos modismos do presente. Estes buscam de forma autônoma construir suas próprias posições, refletindo constantemente sobre as suas experiências e a sua vida intelectual. Buscam elaborar suas convicções individuais, pois estas irão nortear sua postura teórica frente à realidade prática. Ou seja, como diria Bergson (1979, p. 201), escutam o "ponto onde nos sentimos mais interiores à nossa própria vida". Tal processo reflexivo provoca, sutilmente, a autoformação destes profissionais, consistindo em um movimento interno de reflexão sobre si mesmo, seu saber e fazer pedagógico na relação com o outro.

Dessa forma, a conviç̧ão pedagógica colabora para que a utilização de técnicas e a seleção dos conteúdos sejam coadjuvantes na ação do professor. Essa relação entre a 
experiência vivida e a experiência intuitiva aponta para o papel formativo da intuição, na visão bergsoniana, e o papel norteador da convicção pedagógica.

Talvez não seja possível haver uma convicção única para todos os professores ou para todas as dimensões do sujeito. Cada sujeito vai atribuindo sentidos às suas práticas a partir de suas convicções mais íntimas nos diversos espaços onde atua. É possível que um certo número de sujeitos compartilhe das mesmas convicções e as considere em diversos espaços de sua vida; mas a convicção, fruto das vivências intuitivas, é sempre algo singularizado.

Evidentemente que há ainda muito a se investigar sobre a formação de professores e as interfaces que esta tem com a filosofia da educação, mas de antemão já podemos captar a transversalidade das vidas desses professores em diversas dimensões: a pessoal, a social, a profissional, entre outras. Nesta encruzilhada de influências que acompanha nossas vidas, destacamos o papel da intuição que, no processo de construção da convicção, contribui para que muitas das experiências que ocorrem ao longo de nossas vidas fiquem registradas em nossa memória, atuando decisivamente na construção das convicções pessoais.

\section{REFERÊNCIAS BIBLIOGRÁFICAS}

ABBAGNANO, N. Dicionário de Filosofia. São Paulo: Mestre Jou, 1982.

AMORIM, W. L.; HABITZREUTER, V. Contingência e liberdade em Henri Bergson. In: Socitec e-prints. Aracaju, vol. 2, n.1, Jan/Jun de 2006, pp. 32-47.

BERGSON, H. O Pensamento e o Movente. São Paulo: Martins Fontes, 2006.

BERGSON, H. A Evolução Criadora. São Paulo: Martins Fontes, 2005.

BERGSON, H. Matéria e Memória: Ensaio sobre a relação do corpo com o espírito. São Paulo: Martins Fontes, 1999.

BERGSON, H. A intuição filosófica. Lisboa: Edições Colobri, 1994.

BERGSON, H. A Evolução Criadora. Rio de Janeiro: Zahar Editores, 1979.

BERGSON, H. As Duas Fontes da Moral e da Religião. Rio de Janeiro: Zahr editores, 1978.

BERGSON, H. Ensaio sobre os dados imediatos da consciência. Lisboa: Edições 70, s/d.

COELHO, J. G. Bergson: intuição e método intuitivo. In: Trans/Form/Ação. São Paulo, v. 2122, 1998/1999, pp. 151-164.

DEVAUX, A. Bergson. In: HUISMAN, D. Dicionário dos Filósofos. São Paulo: Martins Fontes, 2001, p. 138.

DUROZOI, G.; ROUSSEL, A. Dicionário de Filosofia. São Paulo: Papirus, 1993.

FERNANDES, F. Dicionário de Sinônimos e Antônimos da Língua Portuguesa. São Paulo: Editora Globo, 1998. 
GUIMARÃES, A. M. B.; SILVA, A. J. Bergson e a educação: o "feeling" feminino pode fazer a diferença? Existência e Arte. In: Revista Eletrônica do Grupo PET-Ciências Humanas, Estética e Artes. São João Del-Rei, Número II, Ano II, jan/dez de 2006.

JAPIASSÚ, H.; MARCONDES, D. Dicionário Básico de Filosofia. Rio de Janeiro: Jorge Zahar Editor, 1996.

LUFT, C. P. Dicionário de Sinônimos e Antônimos da Língua Portuguesa. São Paulo: Editora Globo, 1995.

NÓVOA, A. (Org.). Vidas de Professores. Portugal: Porto, 1995.

PARIKH, J.; NEUBAUER, F.; LANK, A. G. Intuição: a nova fronteira da administração. São Paulo: Cultrix, 1998.

RÖHR, F. Educação e Espiritualidade: contribuições para uma compreensão multidimensional da realidade, do homem e da educação. São Paulo: Mercado das Letras, 2013.

SANTOS, B. S. Para um novo senso comum: a ciência, o direito e a política na transição paradigmática. São Paulo: Cortez, 1999.

TORRINHA, F. Dicionário Português - Latino. Porto: Editorial Domingos Barreira, 1939. 